\title{
Electromyographic Analysis of Masseter Muscle after Surgical Correction of Mandibular Prognathism
}

Majid Eshghpour, Seyed Amir Danesh Sani

\begin{abstract}
Sagittal split ramus osteotomy (SSRO) is commonly used for treatment of mandibular prognathism. This study evaluated masseter muscle activity using electromyography device, in patients with mandibular prognathism before and after bilateral SSRO of the mandible.

Twelve prognathic patients (five males and seven females; mean age 20.6 years) were examined. Initial phase of orthodontic treatment was completed in all included patients. Electromyographic activity of masseter muscle was recorded during maximum voluntary clenching as follows: First evaluation: 7 days prior to surgery, second evaluation: 3 months after surgery and third evaluation: 6 months after surgery. Electromyography quantities were significantly decreased 3 months after surgery. Electromyographic activity of masseter muscle was recovered to the preoperative level 6 months after bilateral SSRO of the mandible. SSRO of the mandible is a safe technique for correction of mandibular prognathism and not seriously affects masticatory muscle electromyographic activity.
\end{abstract}

Keywords: Electromyography, Masseter muscle, Mandibular prognathism.

How to cite this article: Eshghpour M, Danesh Sani SA. Electromyographic Analysis of Masseter Muscle after Surgical Correction of Mandibular Prognathism. Int J Head and Neck Surg 2012;3(3):121-124.

Source of support: Nil

Conflict of interest: None

\section{INTRODUCTION}

Over the past 20 years sagital split ramus osteotomy (SSRO) has been recognized as the main surgical procedure for treatment of mandibular prognathism. ${ }^{1,2}$ In 1849, anterior subapical osteotomy was first introduced as a technique of mandibular osteotomy by Hullihen. ${ }^{3}$ Obwegeser and Trauner, ${ }^{4}$ identified SSRO for surgical correction of mandibular deformities in 1955.

Orthognathic surgery can change not only esthetic and occlusion but also have some effects on morphology, physiology and biomechanics of craniofacial skeleton and mastication muscles. ${ }^{5}$

Till now, many studies have been demonstrated effects of orthognathic surgery on masticatory muscles activity. ${ }^{1,6-8}$ SSRO can result in significant changes in thickness and cross-sectional area of masticatory muscles after SSRO which affected the properties of facial morphology. ${ }^{9-13}$

Contributing factors to these morphologic changes are those related to surgical procedure or postoperative complications. ${ }^{14}$ Therefore, evaluation of muscle activity determine the effects of SSRO on masticatory function. Electromyography is a noninvasive method that shows electrical potential of muscles recorded during activity in order to evaluate the amount of dysfunction, impairment and disharmony. ${ }^{15}$ Electromyography (EMG) recordings also help practitioners in application of physical therapy to improve muscle activity. ${ }^{16,17}$

The goal of the current study was to analyze the effect of SSRO on masseter muscle activity by means of EMG in patients with mandibular prognathism.

\section{MATERIALS AND METHODS}

Twelve patients (five males and seven females; mean age 20.6 years), all with mandibular prognathism and a dental angle class III needed mandibular retraction surgery were admitted to the Department of Oral and Maxillofacial Surgery.

The Ethics Committee of the Dental School approved the study protocol. Initial phase of orthodontic treatment was completed in all included patients. Exclusion criteria were defined as history of trauma, neuromascular disease, administration of drugs affecting neuromascular system, orthognathic surgery, postoperative infection and malocclusion.

Lateral cephalography was obtained for the patients, while in the resting position, 1 week before surgery and 3 months after the surgery to find out mandibular changes. Cephalometric assessment was done by same investigators. An acceptable occlusion was obtained in all included patients after surgery.

The EMG activity of masseter muscle was recorded with an electromyographic device (Miotec, Porto Alegre, Brazil) by a neurologist. The skin was disinfected with an alcohol pad to decrease impedance between electrode and body surface. Angle of the mouth and inferior surface of the ear tragus are the main reference points for correct positioning of the electrodes. The distance between electrodes was $3 \mathrm{~cm}$.

The total examination time was subdivided to activity phase and voluntary relaxation period. Patients are in the rest position when sit on the chair with feet flat on the ground. Maximum voluntary clenching of masseter muscle was obtained by biting a piece of cotton roll. 
A series of altering phases occurs during EMG recordings: relaxation: 20 seconds > contraction: 10 seconds > relaxation: 20 seconds > contraction: 10 seconds.

Electromyographic (EMG) activity of masseter muscle was recorded during maximum voluntary clenching as follows: First evaluation: 7 days prior to surgery, second evaluation: 3 months after surgery, and third evaluation: 6 months after surgery.

EMG analysis was performed by routine methods of electromyography amplitude processing include root mean square (RMS), average rectified value (ARV) and integrated EMG (IEMG) activity value. ${ }^{18}$ These values illustrate the degree of the physiological activities in the masseter muscle during maximum voluntary clenching. All data were collected and analysis was performed applying SPSS version 15 (SPSS Inc., Chicago, IL, USA).

\section{RESULTS}

In all evaluation sessions, RMS and ARV values were significantly decreased during contraction period showing that muscle gradually becomes fatigued during the isometric contraction (Figs 1 and 2).

Regarding RMS values, Wilcoxon test revealed that there was a statistically significant difference between first and second sessions $(p=0 / 01)$. Second and third evaluation sessions showed significant difference in RMS values ( $\mathrm{p}=$ $0 / 01$ ). No significant difference was observed in RMS values of first and third sessions ( $p=0 / 77$ ) (Fig. 1).

The same results were observed regarding ARV and IEMG values in different evaluation sessions (Fig. 2).

EMG analysis of masseter muscle revealed that RMS, ARV and IEMG values were significantly decreased 3 months after surgery; but these values showed no significant difference to the preoperative values 6 months after surgery.

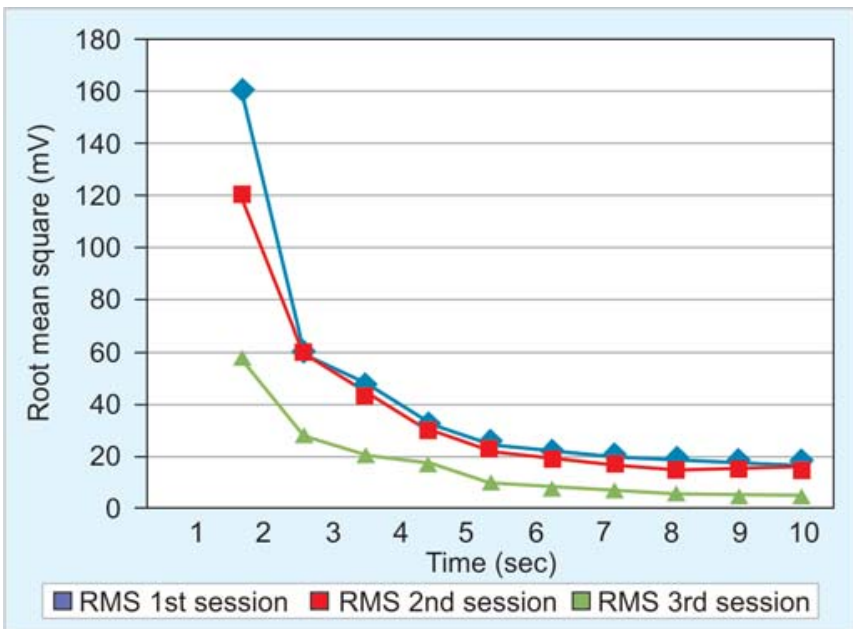

Fig. 1: RMS values of masseter muscle during contraction in different evaluation sessions

\section{DISCUSSION}

Orthognathic surgery is the main therapeutic modality for treatment of dentoskeletal deformities which can affect masticatory muscle activity. ${ }^{19}$ The current study revealed that the degree of physiological activity in the masseter muscle was significantly reduced after surgery but reached the same magnitude after 6 months. Song et $\mathrm{al}^{20}$ evaluated masseter muscle changes after two different surgical procedures. They observed significant changes in experimental muscle mass only in rabbits undergoing osteotomy procedure.

Raustia and Oikarinen ${ }^{21}$ revealed that activity of masseter muscle was significantly reduced 6 weeks after surgery but increased more clearly 1 year after surgery. Increased activity of masseter muscle 1 year after surgery was probably due to maxillomandibular fixation in these patients. Kim et $\mathrm{al}^{22}$ found that the recovery of bite force was significantly affected by surgical method and duration of maxillomandibular fixation. In order to increase bite force after orthognathic surgery, long periods of maxillomandibular fixation should be avoided.

It seems that the activity of masticatory muscles after surgery will be decreased by stabilizing the bones of the jaw. However, masticatory muscle activity improves after the period of the jaw fixation. ${ }^{23}$ In the present work, none of our patients was managed with maxillomandibular fixation which improved masseter muscle activity in 6 months after surgery.

According to Throckmorton et al ${ }^{24}$ study, postoperative decrease in maximum voluntary bite force disappears after 6 months. However, the patients had significantly lower maximum bite forces than the controls for as long as 2 years after surgery. They revealed that neither vertical ramus osteotomy nor SSRO method affect the improvement of maximum bite force after orthognathic surgery.



Fig. 2: ARV values of masseter muscle during contraction in different evaluation sessions 
Kobayashi et $\mathrm{ll}^{25}$ investigated the effect of orthognathic surgery at masticatory function. ${ }^{17}$

Vertical ramus osteotomy and SSRO were the surgical methods applied for correction of mandibular prognathism. According to their study, postoperative EMG of masseter and temporalis muscle increased but EMG quantities were significantly lower in these patients than control subjects with normal occlusion.

In an EMG and radiographic follow-up study, Edlund et $\mathrm{al}^{26}$ demonstrated that the postoperative activity of temporal muscle decreased; however, masticatory efficiency was unchanged. It is noteworthy that they mainly investigated the temporomandibular joint function after SSRO.

Boyd et $\mathrm{al}^{27}$ demonstrated that the masseter muscle histological features and physical activity were changed in response to different surgical methods. They assessed changes in muscle volume by use of magnetic resonance imaging. Westerson et $\mathrm{al}^{28}$ observed atrophic changes with reduced muscle size and fatty replacement of muscle tissue after vertical ramus osteotomy of the mandible. However, Throckmorton et $\mathrm{al}^{24}$ observed no significant difference in the amount of physical activity of masseter muscle in patients treated with SSRO and VRO techniques. Therefore, masseter muscle adoptive response to SSRO and VRO might be similar; however, further investigations are required.

\section{CONCLUSION}

EMG activity of masseter muscle was recovered to the preoperative level 6 months after bilateral SSRO of the mandible. SSRO of the mandible is a safe technique for correction of mandibular prognathism and does not seriously affect masticatory muscle EMG activity.

\section{REFERENCES}

1. Ohkura K, Harada K, Morishima S, Enomoto S. Changes in bite force and occlusal contact area after orthognathic surgery for correction of mandibular prognathism. Oral Surg Oral Med Oral Pathol Oral Radiol Endod 2001;91(2):141-45.

2. Ueki K, Marukawa K, Shimada M, Nakagawa K, Yamamoto E. Changes in occlusal force after mandibular ramus osteotomy with and without Le Fort I osteotomy. Int J Oral Maxillofac Surg 2007;36(4):301-04.

3. Scheideman GB, Kawamura H, Finn RA, Bell WH. Wound healing after anterior and posterior subapical osteotomy. J Oral Maxillofac Surg 1985;43(6):408-16.

4. Martis CS. Complications after mandibular sagittal split osteotomy. J Oral Maxillofac Surg 1984;42(2):101-07.

5. Ueki K, Okabe K, Mukozawa A, et al. Assessment of ramus, condyle, masseter muscle and occlusal force before and after sagittal split ramus osteotomy in patients with mandibular prognathism. Oral Surg Oral Med Oral Pathol Oral Radiol Endod 2009;108(5):679-86.
6. Astrand P. Chewing efficiency before and after surgical correction of developmental deformities of the jaws. Swed Dent J 1974;67(3):135-39.

7. Proffit WR, Turvey TA, Fields HW, et al. The effect of orthognatic on occlusal force. J Oral Maxillofac Surg 1989; 47(2):457-62.

8. Ellis E, Dechow PC, Carlson DS. A comparison of stimulated bite force after mandibular advancement using rigid and nonrigid fixation. J Oral Maxillofac Surg 1989;47(2):1062-68.

9. Throckmorton GS, Ellis E, Buschang PH. Morphological and biomechanical correlates with maximum bite forces in orthognathic surgery patients. J Oral Maxillofac Surg 2000;58(5):515-24.

10. Sassouni V. A classification of skeletal facial types. Am J Orthod 1969;55(3):109-23.

11. Ringqvist $\mathrm{M}$. Isometric bite force and its relation to dimensions of facial skeleton. Acta Odontol Scand 1973;31(1):35-42.

12. Ingervall B. Facial morphology and activity of temporal and lip muscles during swallowing and chewing. Angle Orthod 1976;46(4):372-80.

13. Proffit W, Fields HW, Nixon WL. Occlusal force in normaland long-face adults. J Dent Res 1983;62(5):566-71.

14. Ingervall B, Bitsanis E. A pilot study of the effect of masticatory muscle training on facial growth in long-face children. Eur $\mathrm{J}$ Orthod 1987;9(1):15-23.

15. Goldstein LB. The use of surface electromyography in objective measurement of the muscle function in facial pain/ temporomandibular dysfunction patients. Funct Orthod 2000;17(3):26-29.

16. Dahlström L. Electromyographic studies of craniomandibular disorders: A review of the literature. J Oral Rehabil 1989;16(1): 1-20.

17. Barros TEP, Campolongo GD, de Oliveira RP, Alves A, de Oliveira RJ. Electromyographic study of the masseter muscle after lower third molar surgery. Int J Morphol 2011;29(1): 304-09.

18. Fukuda, TY, Alvarez AS, Nassri LFG, Godoy CMG. Quantitative electromyographic assessment of facial muscles in cross-bite female children. Revista Brasileira de Engenharia Biomédica 2008;24(2):123-30.

19. Cadogan J, Bennun I. Face value: An exploration of the psychological impact of orthognathic surgery. Br J Oral Maxillofac Surg 2011;49(5):376-80.

20. Song HS, Park CHG. Masseter muscle atrophy after Osteotomy of the mandibular angle in rabbits .Plastic Reconstructive Surg 1997;99(1):51-60.

21. Raustia AM, Oikarinen KS. Changes in electric activity of masseter and temporal muscles after mandibular sagittal split osteotomy. Int J Oral Maxillofac Surg 1994;23(3):180-84.

22. Hwan S, Kim YG. Effect of mandibular setback surgery on occlusal force. J Oral Maxillofac Surg 1997;55(2):121-26.

23. Ingervall B, Ridell A, Thilander B. Changes in activity of the temporal, masseter and lip muscles after surgical correction of mandibular prognathism. Int J Oral Surg 1979;8(4):290-300.

24. Throckmorton GS, Buschang PH, Ellis E. Improvement of maximum occlusal forces after orthognathic surgery. J Oral Maxillofac Surg 1996;54(9):1080-86.

25. Kobayashi T, Honma K, Shingaki S, Nakajima T. Changes in masticatory function after orthognatic treatment in patient with mandibular prognathism. Br J Oral Maxillofac Surg 2001;39(4):260-65. 
26. Edlund J, Hansson T, Petersson A, Willmar K. Sagittal splitting of the mandibular ramus. Electromyography and radiologic follow-up study of temporomandibular joint function in 44 patients. Scand J Plast Reconstr Surg 1979;13(3):437-43.

27. Boyd SB, Gonyea WJ, Legan HL. Masseter muscle adaptation following surgical correction of vertical maxillary excess. J Oral Maxillofac Surg 1989;47(9):953-62.

28. Westerson PL, Dahlberg G, Hansson LG, Eriksson L. Osseous and muscular change after vertical ramus Osteotomy. A magnetic resonance imaging study. Oral Surg Oral Med Oral Pathol 1991;72(3):139-45.

\section{ABOUT THE AUTHORS}

\section{Majid Eshghpour}

Assistant Professor, Department of Oral and Maxillofacial Surgery Mashhad Dental School, Mashhad, Iran

\section{Seyed Amir Danesh Sani (Corresponding Author)}

Dental Researcher, Department of Dental Research Center, Mashhad Dental School, Mashhad, Iran, e-mail: amirds_dds@yahoo.com 